Correction

\title{
Correction: de Gonzalo, G. Lipase Catalysed Kinetic Resolution of Racemic 1,2-Diols Containing a Chiral Quaternary Center. Molecules 2018, 23, 1585
}

\author{
Gonzalo de Gonzalo (iD) \\ Departamento de Química Orgánica, Universidad de Sevilla, c/Profesor García González 1, 41012 Sevilla, Spain; \\ gdegonzalo@us.es; Tel.: +34-954559997
}

Received: 11 September 2018; Accepted: 13 September 2018; Published: 29 September 2018

check for updates

The authors wish to make the following corrections to their paper [1]. The authors are sorry to report that the absolute configurations of the 1,2-diols (1-5d) as well as the acetates (1-5e) obtained in this paper are inverted. In order to establish the absolute configuration of these compounds, specific rotation values should be compared with those described in [2] for $(R)-\mathbf{1 d},(R)-\mathbf{4 d}$ and $(R)-\mathbf{5 d}$, instead of the value provided in [3] for $(R)$-ethyl 2-benzyl-2,3-dihydroxypropanoate. This compound is the benzylic analogue of 1,2-diols 1-5d. Compound 6d (ethyl 2-hydroxy-2-hydroxymethyl-4-phenylbutanoate) presents the chiral quaternary center bound to an aliphatic carbon instead of an aromatic one. Thus, specific rotation values cannot be compared with the ones given in [2], and only the relative configurations of $\mathbf{6 d}$ and $\mathbf{6 e}$ are indicated. Consequently, the authors wish to make the following corrections to the paper:

In the enzymatic kinetic resolutions of 1,2-diols containing the chiral center bound to an aromatic carbon atom, $(S)$-1,2-diols $(S)-\mathbf{1 - 5} \mathbf{d}$ and $(R)$-acetates $(R)-\mathbf{1 - 5 e}$ are obtained. With regard to substrate $\mathbf{6 d}$, the 1,2-diol achieved was (-)-6d, whereas the acetate obtained was (+)-6e.

Thus, we replace all over the manuscript $(R)-\mathbf{1}-\mathbf{5 d}$ with $(S)-\mathbf{1}-\mathbf{5 d},(S)-\mathbf{1}-\mathbf{5 e}$ with $(R)-\mathbf{1}-\mathbf{5 e},(R)-\mathbf{6 d}$ with (-)-6d and (S)-6e with (+)-6e. In page 4, replace " $( \pm)-\mathbf{1} \mathbf{e}^{\prime \prime}$ with " $( \pm)-\mathbf{1} \mathbf{d}$ ", " $(S)$-acetates $\mathbf{2}-\mathbf{6 e}$ " with "(R)-acetates $\mathbf{2}-\mathbf{5} \mathbf{e}^{\prime \prime}$.

In page 6 we change "The absolute configuration of the 1,2-diols $(R)-\mathbf{1}-\mathbf{6 d}$ and the acetates (S)-1-6e " with "The absolute configuration of the 1,2-diols $(S)-\mathbf{1}-\mathbf{5} \mathbf{d}$ and the acetates $(R)-\mathbf{1}-\mathbf{5} \mathbf{e}^{\prime \prime}$, and " $(R)$-ethyl 2-benzyl-2,3-dihydroxypropanoate [23]." to " $(R)$-ethyl 2,3-dihydroxy-2-phenylpropanoate [(R)-1d], (R)-ethyl 2,3-dihydroxy-2-(4-methoxyphenyl)propanoate $[(R)-4 \mathbf{d}]$, and (R)-ethyl 2,3-dihydroxy-2-(tiophen-2-yl)propanoate, [(R)-5d] in reference [26]."

The scheme of Table 2 is to be replaced:

Table 2. Lipase-catalysed acylation of rac-ethyl 2,3-dihydroxy-2-phenylprpanoate (1d) at different reaction conditions.

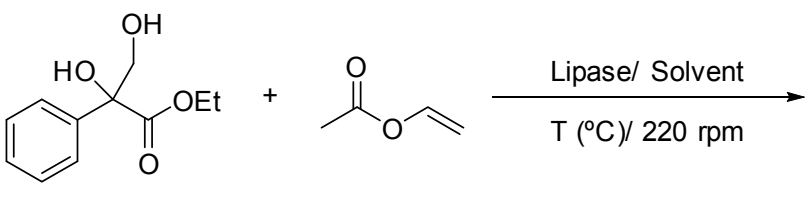

$( \pm)-1 d$<smiles>CCOC(=O)[C@](O)(CO)c1ccccc1</smiles>

$(R)-1 \mathbf{d}$<smiles>CCOC(=O)[C@](O)(OC(C)=O)c1ccccc1</smiles>

$(S)-1 e$

with

Table 2. Lipase-catalysed acylation of rac-ethyl 2,3-dihydroxy-2-phenylpropanoate (1d) at different reaction conditions. 


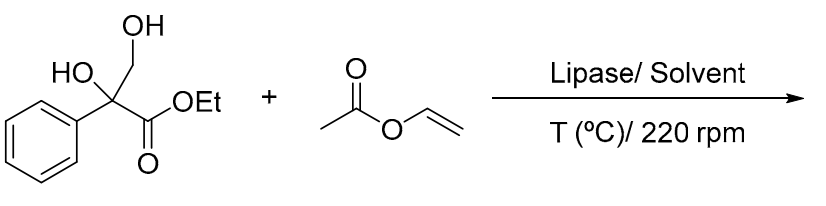

$( \pm)-1 d$<smiles>CCOC(=O)[C@@](O)(CO)c1ccccc1</smiles>

(S)-1d<smiles>CCOC(=O)[C@](O)(COC(C)=O)c1ccccc1</smiles>

$(R)-1 e$

with

The scheme of Table 3 is also to be replaced:

Table 3. PSL-C catalysed kinetic resolution of racemic diols $\mathbf{2}-\mathbf{6 d}$ in tert-butyl methyl ether (TBME) at $30{ }^{\circ} \mathrm{C}$ using vinyl acetate as the acyl donor.<smiles>[R20]C(=O)C(C)(CO)C([R])(O)CO</smiles>

$( \pm)-2-6 d$

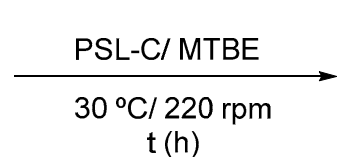

$t(h)$<smiles>[R20]OC(=O)C1CCC([R1])(O)C1</smiles>

$(R)-2-6 \mathrm{~d}$

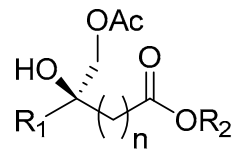

(S)-2-6e with

Table 3. PSL-C catalysed kinetic resolution of racemic diols $\mathbf{2}-\mathbf{6 d}$ in tert-butyl methyl ether (TBME) at $30{ }^{\circ} \mathrm{C}$ using vinyl acetate as the acyl donor.<smiles>[R20]C(=O)CC([R])(O)CO</smiles>

$( \pm)-2-6 d$<smiles>[R20]C(=O)C(=O)C([R])(O)CO</smiles>

(S)-2-5d<smiles>[R20]C(=O)CC([R])(C)CO</smiles>

$(-)-6 d$
$(R)-2-5 \mathrm{e}$ $\mathrm{t}(\mathrm{h})$<smiles>[R20]OC(=O)C(C)C([R])(O)COC(C)=O</smiles>

$(+)-6 e$

The author would like to apologize for any inconvenience caused to the readers. The manuscript will be updated and the original will remain online on the article webpage, with a reference to this Correction.

\section{References}

1. de Gonzalo, G. Lipase Catalysed Kinetic Resolution of Racemic 1,2-Diols Containing a Chiral Quaternary Center. Molecules 2018, 23, 1585. [CrossRef] [PubMed]

2. Crespo-Peña, A.; Monge, D.; Martín-Zamora, E.; Álvarez, E.; Fernández, R.; Lassaletta, J.M. Asymmetric Formal Carbonyl-Ene Reactions of Formaldehyde tert-Butyl Hydrazone with $\alpha$-Keto Esters: Dual Activation by Bis-urea Catalysts. J. Am. Chem. Soc. 2012, 134, 12912-12915. [CrossRef] [PubMed]

3. Jew, S.; Roh, E.; Baek, E.; Mireille, L.; Kim, H.; Jeong, B.; Park, M.; Park, H. Asymmetric synthesis of (R)-(+)-etomoxir via enzymatic resolution. Tetrahedron Asymmetry 2000, 11, 3395-3401. [CrossRef] 